\title{
Bacopa monnieri extract increases rat coronary flow and protects against myocardial ischemia/reperfusion injury
}

Sirintorn Srimachai ${ }^{1,2}$, Sylvie Devaux ${ }^{3}$, Celine Demougeot ${ }^{3}$, Sarawut Kumphune ${ }^{4,5}$, Nina D. Ullrich ${ }^{6,7}$, Ernst Niggli ${ }^{6}$, Kornkanok Ingkaninan ${ }^{8}$, Natakorn Kamkaew ${ }^{2,9}$, C. Norman Scholfield ${ }^{8}$, Sompol Tapechum ${ }^{1}$ and Krongkarn Chootip ${ }^{2^{*}}$

\begin{abstract}
Background: This study explored Bacopa monnieri, a medicinal Ayurvedic herb, as a cardioprotectant against ischemia/reperfusion injury using cardiac function and coronary flow as end-points.

Methods: In normal isolated rat hearts, coronary flow, left ventricular developed pressure, heart rate, and functional recovery were measured using the Langendorff preparation. Hearts were perfused with either (i) Krebs-Henseleit (normal) solution, (control), or with 30,100 $\mathrm{g} / \mathrm{ml}$ B. monnieri ethanolic extract (30 min), or (ii) with normal solution or extract for $10 \mathrm{~min}$ preceding no-perfusion ischemia $(30 \mathrm{~min}$ ) followed by reperfusion (30 min) with normal solution. Infarct volumes were measured by triphenyltetrazolium staining. L-type $\mathrm{Ca}^{2+}{ }_{-}$Currents $\left(\mathrm{I}_{C a}, L\right)$ were measured by whole-cell patching in $\mathrm{HL}-1$ cells, a mouse atrial cardiomyocyte cell line. Cytotoxicity of B. monnieri was assessed in rat isolated ventricular myocytes by trypan blue exclusion.

Results: In normally perfused hearts, B. monnieri increased coronary flow by $63 \pm 13 \%(30 \mathrm{\mu g} / \mathrm{ml})$ and $216 \pm 21 \%$ $(100 \mu \mathrm{g} / \mathrm{ml})$, compared to control $(5 \pm 3 \%)(n=8-10, p<0.001)$. B. monnieri treatment preceding ischemia/reperfusion improved left ventricular developed pressure by $84 \pm 10 \%(30 \mu \mathrm{g} / \mathrm{ml}), 82 \pm 10 \%(100 \mu \mathrm{g} / \mathrm{ml})$ and $52 \pm 6 \%$ (control) compared to pre- ischemia/reperfusion. Similarly, functional recovery showed a sustained increase. Moreover, $B$. monnieri $(100 \mathrm{\mu g} / \mathrm{ml})$ reduced the percentage of infarct size from $51 \pm 2 \%$ (control) to $25 \pm 2 \%(n=6-8, p<0.0001)$. B. monnieri $(100 \mu \mathrm{g} / \mathrm{ml})$ reduced $I_{C a}$, by $63 \pm 4 \%$ in $\mathrm{HL}-1$ cells. Ventricular myocyte survival decreased at higher concentrations $(50-1000 \mu \mathrm{g} / \mathrm{ml})$ B. monnieri.
\end{abstract}

Conclusions: B. monnieri improves myocardial function following ischemia/reperfusion injury through recovery of coronary blood flow, contractile force and decrease in infarct size. Thus this may lead to a novel cardioprotectant strategy.

Keywords: Bacopa monnieri, Brahmi, Heart, Coronary blood flow, Ischemia/reperfusion, Cardiac function, Myocardial infarction

\footnotetext{
*Correspondence: krongkarnc@nu.ac.th; krongkarnc@gmail.com

${ }^{2}$ Department of Physiology, Faculty of Medical Science, Naresuan University,

Phitsanulok 65000, Thailand

Full list of author information is available at the end of the article
} 


\section{Background}

Disease of the myocardial vasculature including the coronary artery is a major cause of disability and death in spite of widespread application of highly efficacious cardiovascular drugs. Myocardial infarction (MI) most commonly arises from an unstable atheroma forming fragments and clots that occlude downstream vessels culminating in regional myocardial ischemia [1]. The resultant energy failure has numerous cytopathological consequences, including changes of $\mathrm{pH}$ and $\mathrm{Na}^{+}$levels, subsequently leading to reversal of $\mathrm{Na}^{+} / \mathrm{Ca}^{2+}$ exchange, which in turn results in cytosolic $\mathrm{Ca}^{2+}$ loading and activation of proteolytic enzymes mediating necrosis [2]. Mitochondrial $\mathrm{Ca}^{2+}$ homeostasis also fails, leading to disruption of the electron transport chain, cytochrome $\mathrm{C}$ release and initiation of apoptosis. However, these changes are slow during sustained occlusion [2] but most damage begins on reperfusion. Glucose is shunted into glycolysis producing lactic acid and mitochondrial beta-fatty acid oxidation [2]. Early reperfusion is accompanied by excessive superoxide production [3] and consequently leads to other reactive species which increase cell damage and to further cytosolic $\mathrm{Ca}^{2+}$ loading [4]. Fragments of damaged cells then activate resident immune cells and immune receptors on endothelial cells, which in turn secrete inflammatory cytokines and adhesion proteins, respectively. Endothelial cells generate further superoxide via adherent xanthine oxidase, cytokine activation of nicotinamide adenine dinucleotide phosphate (NADPH) oxidase, and oxidised nitric oxide (NO) synthase [5]. Endothelial cells not only lose their vasorelaxant influence over vascular smooth muscle, but they release vasoconstrictors, especially endothelin-1 [6], which further exacerbates the conditions causing MI. Endothelial injury manifests as cell blebbing, swelling and plugging culminates in "no-reflow" [7]. Thus we have a potent cytotoxic combination of $\mathrm{Ca}^{2+}$, superoxide, inflammation and vasoconstriction, all of which conspire over the ensuing minutes-hours in myocardial cell death.

Targeting these pathologies individually produces improved recoveries in experimental animals provided the protectant is present before ischemia begins, but they have failed in translation. Thus at present, the standard treatments focus on atherosclerosis by using thrombolytics, anticoagulants or angioplasty. Clinical applications targeting mitochondria have met with some limited positive outcomes [2, 8]. Nevertheless, it is clear that for any protectant to be useful, it would have to be administered prophylactically to high risk patients, act against the major reperfusion pathologies, be cheap and have low toxicity and ideally, help to reduce the initial risk of MI. It is unlikely that any classical single substance or drug could perform in this manner, but several multifunctional herbals have the potential to fulfill such a role.

They include, a medicinal Ayurvedic herb, which is thought to improve cardiovascular function. Thus, oral B. monnieri given to rats for three weeks reduced biochemical and histopathological perturbations caused by ischemia/reperfusion (I/R), while increasing myocardial antioxidant enzymes and reducing myocardial apoptotic signaling proteins [9]. Over-dosing rats with isoproterenol reduced endogenous antioxidant enzymes and increased lipid peroxidation, but less so in those animals which had been chronically treated with $B$. monnieri [10]. Necrosis and markers of myocardial injury were also reduced.

There is also some evidence that B. monnieri improves systemic vascular function. It relaxes a wide range of arteries [11], partly through endothelial NO release and in vascular smooth muscle by inhibiting $\mathrm{Ca}^{2+}$ influx and $\mathrm{Ca}^{2+}$ release from the sarcoplasmic reticulum [11]. Nevertheless, chronic oral administration of B. monnieri to rats for 12 weeks increased cerebral blood flow without changing blood pressure [12]. This is particularly important because $B$. monnieri has been traditionally used to enhance memory and several clinical trials suggest that it does have nootropic actions $[13,14]$. Furthermore, it is neuroprotective $[15,16]$ and the mechanism of action is mainly related to its antioxidant and antiinflammatory properties [16-18]. Recently, we have shown that B. monnieri had no signs of toxicity in either acute or chronic oral toxicity tests of both male and female rats, indicating that it is relatively safe [19].

Clearly, several lines of evidence point to $B$. monnieri having potentially favorable cardiovascular actions arising from the hemodynamic changes and protective effects in vulnerable tissues as well as reducing some of the pathological changes contributing to $I / R$ injury. Nevertheless, it is unclear whether these effects of $B$. monnieri translate directly to improving the function of the myocardium or whether they could ameliorate the damage following cessation and restoration of blood flow, i.e., I/R injury. To answer this, we aimed to show that an extract of B. monnieri could improve myocardial perfusion in normally beating isolated rat hearts and to show that it produces an independent acute recovery in cardiac function after $I / R$ while at the same time not creating cellular toxicity in isolated ventricular myocytes.

\section{Methods}

\section{Preparation of $B$. monnieri extract}

The aerial part of $B$. monnieri was collected from Phetchaburi province, Thailand, and identified by Associate Professor Wongsatit Chuakul, Faculty of Pharmacy, Mahidol University, Thailand. The voucher specimen (Phrompittayarat 001) was kept at the 
Pharmaceutical Botany Mahidol Herbarium, Mahidol University, Thailand. B. monnieri was extracted using 95\% ethanol and its total saponin content, $4.19 \%(\mathrm{w} / \mathrm{w})$ comprising bacoside $\mathrm{A}_{3}(0.74 \%)$, bacopaside I $(0.93 \%)$, bacopaside II (0.98\%) bacopaside X (0.53\%), and bacopasaponin C (1.00\%), was determined by high pressure liquid chromatography as previously reported $[20,21]$. The extract was dried and stored at $4{ }^{\circ} \mathrm{C}$ until use. Its yield was $10 \%$ (w/w of the dried plant). The B. monnieri extract was dissolved in Krebs-Henseleit buffer (KHB) $(\mathrm{mM}): \mathrm{NaCl}, 118$; $\mathrm{NaHCO}_{3}, 25 ; \mathrm{KH}_{2} \mathrm{PO}_{4}, 1.2 ; \mathrm{KCl}, 4.5 ; \mathrm{CaCl}_{2}, 1.36 ; \mathrm{MgSO}_{4}$, 1.2 and glucose 11 adjusted to $\mathrm{pH}$ 7.4. It was stirred for $30 \mathrm{~min}$ and sonicated in an ultrasonic tank at $37{ }^{\circ} \mathrm{C}$ for another $30 \mathrm{~min}$. Prior to use, the KHB and the solutions of $B$. monnieri extract were filtered through a $0.8 \mu \mathrm{m}$ Millipore filter to remove insoluble particles.

\section{Animals}

Adult male Wistar rats (200-250 g, 7-8 weeks old) were obtained from the National Laboratory Animal Centre, Mahidol University, Salaya, Nakhorn Pathom, Thailand or Charles River, L'Arbresle, France. All experimental protocols were approved by the Animal Ethics Committee (No. NU-AE530613 and NU-AE590203), Naresuan University, Phitsanulok, Thailand and by the local committee for ethics in animal experimentation (No. 2012012-CD, date 05/09/2012), Faculty of Medicine and Pharmacy, Université de Franche Comte, Besançon, France, and complied with the US National Institutes of Health (NIH publication No. 85-2, revised 1996). Rats were kept in polysulfone shoe box cage (3-4 rats/cage) bedded with autoclaved corn cob, in temperaturecontrolled rooms $\left(22 \pm 2{ }^{\circ} \mathrm{C}\right)$, at $50-60 \%$ humidity, with a reversed 12:12 h diurnal cycle and standard diet and RO water provided ad libitum. Animals were randomly allocated for ex vivo treatment. The sample size was calculated using $\mathrm{R}$ program $(\alpha=5 \%$, mean difference $=$ $15, \mathrm{SD}=10$, power $=80 \%$ ).

\section{Preparation of Langendorff heart perfusion and protocols Effect of $B$. monnieri on normal and $I / R$ hearts}

Rats were anesthetized with sodium pentobarbital (50 mg/kg, intraperitoneally) followed by heparin (250 $\mathrm{UI} / \mathrm{kg}$, intravenously). The level of anesthesia was assessed by toe pinch and corneal reflex before the surgery. The hearts were then rapidly removed and immersed in ice-cold KHB to stop contractions, and the myocardium was perfused retrogradely with KHB using the Langendorff method at a constant perfusion pressure of $80 \mathrm{~cm}$ of water $(7.8 \mathrm{kPa})$. The perfusate was bubbled with $95 \%$ oxygen and $5 \%$ carbon dioxide and maintained at $37{ }^{\circ} \mathrm{C}$. To measure left ventricular end diastolic pressure (LVEDP), a water-filled latex balloon $(4 \times 8 \mathrm{~mm}$, EMKA Technologies, Paris, France) was inserted into the left ventricle and connected to a pressure transducer (682002, Becton Dickinson, Sandy, Utah, USA) and a Gould TA240 Physiograph (Gould Instrument Systems, Courtaboeuf, France). The pressure within the balloon was adjusted to $2-8 \mathrm{mmHg}$, i.e., equivalent to the normal LVEDP [22].

The intraventricular pressure and heart rate $(\mathrm{HR})$ were continuously recorded. The left ventricular developed pressure (LVDP) calculated as left ventricular systolic pressure minus LVEDP, was used as an indicator of left ventricular systolic function. Total coronary flow was measured by collecting aliquots of coronary venous effluent. All hemodynamic parameters were measured at 2 min intervals. The hearts were stabilized for 10 $20 \mathrm{~min}$ and then the following two experimental protocols (Table 1 ) were carried out (54 rats, $n=8-10$ /group).

The concentrations of $B$. monnieri extract were based on earlier in vitro studies where the $\mathrm{IC}_{50}$ was around $100 \mu \mathrm{g} / \mathrm{ml}$ for inducing vasorelaxation in small resistance arteries [11].

\section{Effect of B. monnieri on myocardial infarct size}

Rat hearts were isolated and perfused using the Langendorff method as described above. The hearts were preperfused with KHB (control) or KHB supplemented with $100 \mu \mathrm{g} / \mathrm{ml} \mathrm{B}$. monnieri for $30 \mathrm{~min}$ prior to $30 \mathrm{~min}$ global ischemia followed by $2 \mathrm{~h}$ reperfusion, sufficient to allow histological changes to develop [23] (14 rats, $n=8$ for control, $n=6$ for treatment). After $2 \mathrm{~h}$ of reperfusion, hearts were perfused for $5 \mathrm{~min}$ with $10 \mathrm{ml}$ of $1 \%(\mathrm{w} / \mathrm{v})$ triphenyltetrazolium chloride (TTC) (Sigma, St. Louis, MO, USA), then removed and placed in 1\% TTC solution at $37{ }^{\circ} \mathrm{C}$ for $10 \mathrm{~min}$ [23]. The hearts were incubated in $2.5 \%$ glutaraldehyde for $1 \mathrm{~min}$, and set in $5 \%$ agarose before sectioning in $750 \mu \mathrm{m}$ thick slices. All slices were incubated in $10 \%(\mathrm{v} / \mathrm{v})$ formaldehyde overnight at room temperature before re-hydration overnight with

Table 1 Experimental design of B. monnieri effect on normal and $I / R$ hearts

\begin{tabular}{|c|c|}
\hline Group & Treatment \& Protocol \\
\hline \multirow[t]{4}{*}{ Normal hearts } & 1) $\mathrm{KHB}$ (control, $n=9$ ) \\
\hline & 2) $30 \mu \mathrm{g} / \mathrm{ml}$ B. monnieri extract $(n=10)$ \\
\hline & 3) $100 \mu \mathrm{g} / \mathrm{ml}$ B. monnieri extract $(n=8)$ \\
\hline & $\begin{array}{l}\text { Protocol: Isolated hearts were perfused with KHB alone } \\
\text { or KHB containing B. monnieri extract for } 30 \text { min (Fig. 1) }\end{array}$ \\
\hline \multirow[t]{4}{*}{ I/R hearts } & 1) $\mathrm{KHB}$ (control, $n=9$ ) \\
\hline & 2) $30 \mu \mathrm{g} / \mathrm{ml} \mathrm{B.} \mathrm{monnieri} \mathrm{extract}(n=9)$ \\
\hline & 3) $100 \mu \mathrm{g} / \mathrm{ml} \mathrm{B.} \mathrm{monnieri} \mathrm{extract}(n=9)$ \\
\hline & $\begin{array}{l}\text { Protocol: Isolated hearts were perfused with KHB alone } \\
\text { or KHB containing B. monnieri extract for } 10 \text { min and } \\
\text { then perfusion stopped for } 30 \text { min to emulate global } \\
\text { myocardial ischemia, after which } 30 \text { min perfusion was } \\
\text { resumed with normal oxygenated KHB (Fig. 2). }\end{array}$ \\
\hline
\end{tabular}


phosphate buffer saline (PBS) at $4{ }^{\circ} \mathrm{C}$. The heart sections were scanned and planimetry was carried out and surface area of the whole, and TTC-negative, myocardium was transformed to volume [23]. The TTCnegative infarction volume was expressed as a percentage of heart volume. All analyses of infarct size were done by an investigator, who was blinded with regard to the group assignments.

\section{Electrophysiological measurements of the L-type $\mathrm{Ca}^{2+}$ current}

Effect of B. monnieri $(100 \mu \mathrm{g} / \mathrm{ml})$ on L-type $\mathrm{Ca}^{2+}$ current $\left(\mathrm{I}_{\mathrm{Ca}}, \mathrm{L}\right)$ was studied in HL-1 cells (kind gift from Prof. Dr. William C. Claycomb, Louisiana State University Medical Center, LA, USA). This cell line, derived from an atrial tumor lineage of the AT-1 mouse, spontaneously contracts and retains the phenotypic characteristics of cardiomyocytes [24], including the expression of L-type $\mathrm{Ca}^{2+}$ channels. Inhibition of $\mathrm{I}_{\mathrm{Ca}}, \mathrm{L}$ by nifedipine was previously demonstrated in HL-1 cells as shown in Additional file 1: Figure S1. The whole-cell patch clamp technique was used for recording of $\mathrm{I}_{\mathrm{Ca}}, \mathrm{L}$. The experimental protocol was adopted from a previous study [25]. The composition of the bath solution (i.e., normal Tyrode's solution) was (mM): $\mathrm{NaCl}, 140 ; \mathrm{KCl}, 5.4 ; \mathrm{MgCl}_{2}$, 1.1; $\mathrm{CaCl}_{2}, 2$; HEPES, 5; glucose, 10 and adjusted $\mathrm{pH}$ to 7.4, osmolality, $310 \mathrm{mOsm}$. Patch pipettes were fabricated from capillary glass tubing (Borosilicatestandard wall with filament, $1.50 \mathrm{~mm}$ OD). Internal solution was composed of (mM): $\mathrm{NaCl}, 8 ; \mathrm{MgCl}_{2}, 5.9$; HEPES, 20; Cs aspartate, 120; TEA-Cl, 20; $\mathrm{K}_{2}$-ATP, 5 ( $\mathrm{pH}$ 7.2, osmolality, $290 \mathrm{mOsm})$. The pipette resistance was 3-5 $\mathrm{M} \Omega$ in the bath solution. Cells were locally perfused with Tyrode's solution plus $\mathrm{CsCl}_{2}$ (5 mM) to block $\mathrm{K}^{+}$channels. $\mathrm{I}_{\mathrm{Ca}}$, L was recorded using following protocols [25]: holding membrane potential was kept at $-80 \mathrm{mV}$. A pre-step to $-40 \mathrm{mV}$ for $1500 \mathrm{~ms}$ inactivated $\mathrm{Na}^{+}$and T-type $\mathrm{Ca}^{2+}$ channels, then a test-step to $+10 \mathrm{mV}$ for $400 \mathrm{~ms}$ was applied to measure L-type $\mathrm{Ca}^{2+}$ currents. Control $\mathrm{I}_{\mathrm{Ca}}$, L was recorded 3 times to obtain consistency of the current of the cell chosen. Then, each cell was locally perfused with $100 \mu \mathrm{g} / \mathrm{ml} \mathrm{B.} \mathrm{monnieri} \mathrm{extract} \mathrm{dissolved} \mathrm{in}$ Tyrode's solution containing $\mathrm{CsCl}_{2}$ for $1 \mathrm{~min}$. Subsequently, currents were recorded in the presence of the extract. Current signals were recorded with an Axopatch 200B patch-clamp amplifier (Axon Instruments, Foster City, CA) connected to a $50 / 60 \mathrm{~Hz}$ Noise Eliminator (Hum Bug, Quest Scientific, Canada). Data were collected using a custom-written program (Myoclamp V2.4.1 software) for Windows. Currents were analyzed by using IGOR Pro6 software (Wave-Metrics). The average effect of the extract on
$\mathrm{I}_{\mathrm{Ca}}$, L was expressed as percentage change of control $\mathrm{I}_{\mathrm{Ca}, \mathrm{L}}$ from the same cell.

\section{Cytotoxicity of B. monnieri Isolation of rat ventricular myocytes and culture}

Ventricular myocytes were isolated from rat hearts using collagenase as previously described [23, 26]. Hearts were excised and initially perfused in the Langendorff apparatus for $5 \mathrm{~min}$ with Tyrode's solution containing $(\mathrm{mM}): \mathrm{NaCl}, 130 ; \mathrm{KCl}, 4.5 ; \mathrm{MgCl}_{2}$ 1.4; $\mathrm{NaH}_{2} \mathrm{PO}_{4}, 0.4 ; \mathrm{CaCl}_{2}, 0.75 ;$ [N-(2-hydroxyethyl) piperazine $\mathrm{N}^{\prime}$-(2-ethanesulfonic acid)] HEPES 4.2, taurine 20, creatine 10, glucose 10, pH 7.3 and gassed with $100 \% \mathrm{O}_{2}$ at $37{ }^{\circ} \mathrm{C}$ and then perfused with $\mathrm{Ca}^{2+}$ free Tyrode's solution containing $100 \mu \mathrm{M}$ EGTA for another $4 \mathrm{~min}$. This was followed by Tyrode's solution containing $100 \mu \mathrm{M} \quad \mathrm{CaCl}_{2}$ and $1 \mathrm{mg} / \mathrm{ml}$ Worthington type II collagenase for $8 \mathrm{~min}$. The ventricles were then cut into approximately $1 \mathrm{~mm}^{3}$ pieces and incubated in $10 \mathrm{ml}$ of this collagenase solution for 7 min with regular triturating using a Pasteur pipette until cells were released. Isolated myocytes were separated from undigested ventricular tissue by filtering through cell strainer. Isolated myocytes were allowed to settle into a loose pellet and the supernatant was removed and replaced with Tyrode's solution containing $1 \%$ fetal bovine serum albumin and $500 \mu \mathrm{M} \mathrm{CaCl}$. In the next step, the supernatant was removed and replaced with Tyrode's solution containing $1 \mathrm{mM} \mathrm{CaCl}_{2}$. The cell pellet was washed at room temperature with M199 culture medium containing $100 \mathrm{IU} / \mathrm{ml}$ penicillin/streptomycin. The myocytes were resuspended in modified M199 (containing $2 \mathrm{mM}$ creatine, $2 \mathrm{mM}$ carnitine, and $5 \mathrm{mM}$ taurine).

\section{Determination of cell viability}

Cell viability was assessed by trypan blue exclusion assay [26]. After cell plating, the isolated cardiac myocytes were replenished with modified M199 culture medium (control) or medium containing B. monnieri extract $(10-1000 \mu \mathrm{g} / \mathrm{ml})$ for $1 \mathrm{~h}$. Then the supernatants were removed, the cells were resuspended in $50 \mu \mathrm{l} 0.4 \%$ trypan blue solution and incubated for $5 \mathrm{~min}$. After that, supernatants were removed and replaced with PBS solution. One hundred cells in each well $(n=3)$ were randomly counted under a light microscope. The cell viability was calculated as number of unstained cells divided by total number of cells and expressed as a percentage.

\section{Drugs and solution}

All chemicals were purchased from Sigma (St. Louis, MO, USA or Saint Quentin Fallavier, France). M199 medium and fetal bovine serum were from Gibco BRL, 
Life Technologies, Inc. (New York, USA). Type II collagenase was obtained from Worthington (Lakewood, NJ, USA).

\section{Statistical and data analysis}

All data are presented as mean \pm standard error of mean (SEM) of $n$ animals or cells. Comparisons were assessed using analysis of variance (two-way ANOVA) followed by Tukey's test or Student $t$-test as appropriate. Statistical significance was considered at $p$ values $<0.05$. To compare the effects of $B$. monnieri with controls, all hemodynamic parameters were normalized to the data value obtained after the $10 \mathrm{~min}$ stabilization period, and were expressed as \%coronary flow, \%LVDP, \%HR, and $\%$ functional recovery, a global index of cardiac contractile function, calculated as [(HR TRx $\times$ LVDP $\mathrm{TRx} \times 100)$ / HR TP10 $\times$ LVDP TP10] where TRx represents the time of reperfusion at $\mathrm{x}$ min and TP10 relates to the value at $10 \mathrm{~min}$ of the perfusion during stabilization period.

\section{Results}

B. monnieri increased coronary flow in normal hearts

In normally perfused isolated rat hearts, during stabilization, all hemodynamic parameters including coronary flow (Fig. 1a), LVDP and HR remained constant and similar in all treatment groups. Application of 30 or $100 \mu \mathrm{g} / \mathrm{ml} \mathrm{B.} \mathrm{monnieri}$ for $30 \mathrm{~min}$ produced a concentration-dependent increase in coronary flow (Fig. 1b) and LVDP (Fig. 1c). The coronary flow was 1.6fold increased in the presence of B. monnieri at $30 \mu \mathrm{g} /$ $\mathrm{ml}($ mean $=168 \pm 13 \%, n=10)$, and 3.1-fold at $100 \mu \mathrm{g} / \mathrm{ml}$ (mean $=321 \pm 21 \%, n=8)$ compared to control (mean = $105 \pm 3 \%, n=9$ ) (Fig. 1e). There were also small increases in LVDP (Fig. 1c, e), but no change in HR (Fig. 1d, e) in response to both concentrations of $B$. monnieri.

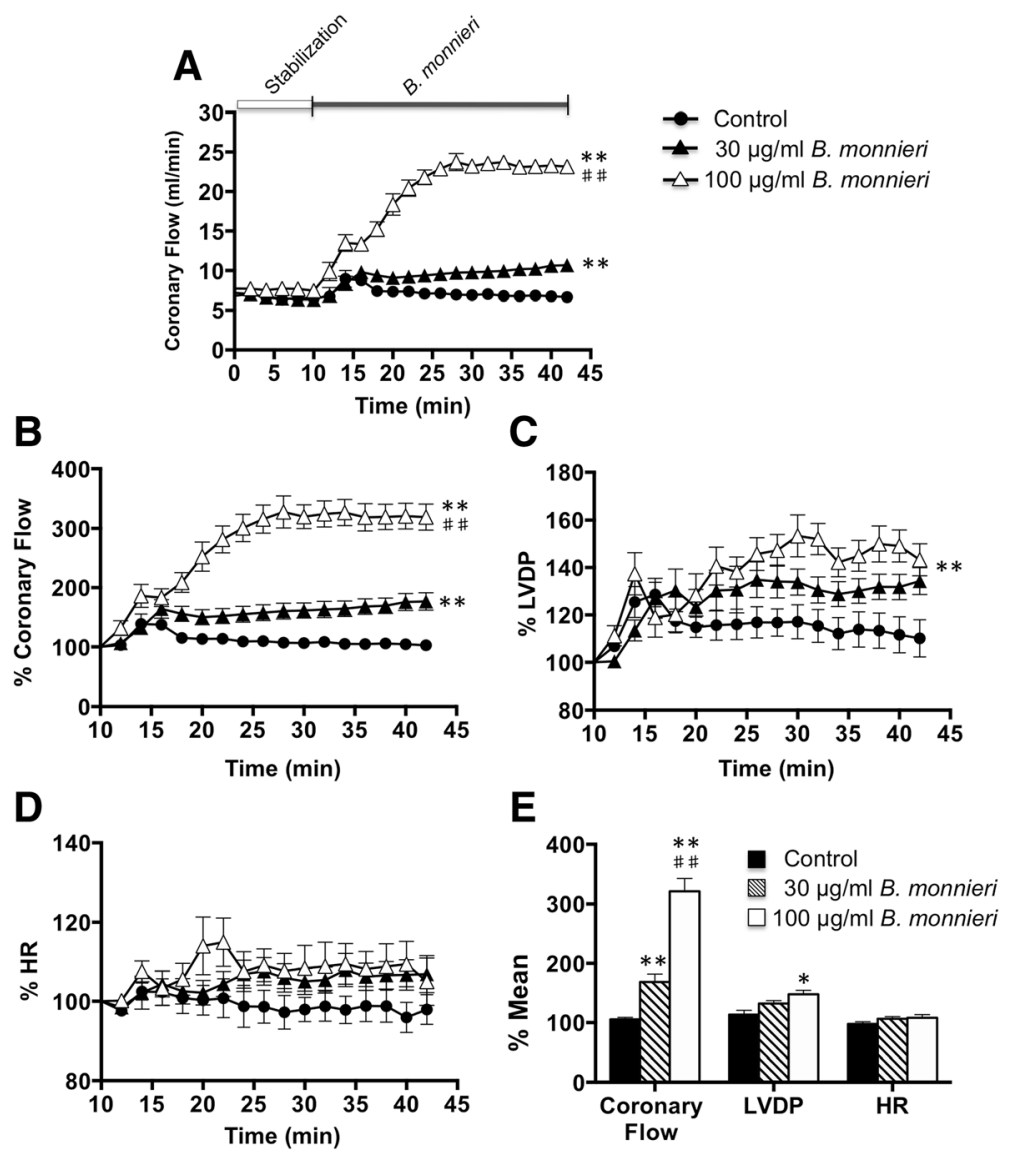

Fig. 1 B. monnieri improved hemodynamics in isolated rat hearts. a coronary flow ( $\mathrm{ml} / \mathrm{min}$ ) using normal perfusate (control) and perfusate containing 30 or $100 \mu \mathrm{g} / \mathrm{ml}$ B. monnieri extract for $30 \mathrm{~min}$, b coronary flow, \%, c LVDP, \%, d HR, \%: b-d expressed as percentage of mean data from the same heart compared to the 10 min stabilization using normal perfusate and $\mathbf{e}$ mean expressed as the average of each parameter after application of normal perfusate or perfusate containing B. monnieri extract for 15 min onward. Data are expressed as mean \pm SEM ( $n=8-10$ hearts) and ${ }^{*} p<0.05,{ }^{* *} p<0.001$ for $30,100 \mu \mathrm{g} / \mathrm{ml} \mathrm{B.} \mathrm{monnieri} \mathrm{compared} \mathrm{to} \mathrm{control,}{ }^{\# \#} p<0.001$ for $30 \mu \mathrm{g} / \mathrm{ml}$ compared to $100 \mu \mathrm{g} / \mathrm{ml}$ B. monnieri 


\section{B. monnieri improved recovery after I/R}

B. monnieri extract was added to the perfusate for $10 \mathrm{~min}$ whereupon coronary flow increased as above. The perfusion was then stopped for $30 \mathrm{~min}$ to emulate global ischemia after which perfusion was restored for a further $30 \mathrm{~min}$ (Fig. 2a). In the control group $(n=9)$, all the hemodynamic parameters were substantially reduced compared to before ischemia (Fig. 2b-e). However, pretreatment with 30 or $100 \mu \mathrm{g} / \mathrm{ml} \mathrm{B}$. monnieri improved cardiac function in I/R heart. Coronary flow was immediately restored to $90 \pm 10 \%(n=9)$, and $111 \pm 7 \%(n=9)$ with pre-exposure to 30 and $100 \mu \mathrm{g} / \mathrm{ml} \mathrm{B.} \mathrm{monnieri,} \mathrm{re-}$ spectively (Fig. 2b). Although coronary flow declined, this was always higher in the $B$. monnieri pre-treated groups at every time point compared to those without $B$. monnieri $(p<0.001)$. LVDP as a measure of myocardial contractile force, gradually increased in B. monnieritreated groups and maintained after reperfusion for 20 min onwards $(52 \pm 6 \%, 84 \pm 10 \%, 82 \pm 10 \%$, for control, $30 \mu \mathrm{g} / \mathrm{ml}$ and $100 \mu \mathrm{g} / \mathrm{ml} \mathrm{B.} \mathrm{monnieri,} \mathrm{respectively,}$ $p<0.001$ for B. monnieri compared to control) (Fig. 2c). Likewise, functional recovery showed a sustained increase (Fig. 2e). HR was depressed on initial reperfusion, but there was no clear change during the recovery period (Fig. 2d).

Pretreatment of $B$. monnieri reduced myocardial infarction An ex vivo global ischemia for $30 \mathrm{~min}$ followed by $2 \mathrm{~h}$ reperfusion resulted in the myocardial infarction up to $51 \pm 2 \%$ of ventricular volume $(n=8)$ (Fig. 3, control). Pretreatment with $100 \mu \mathrm{g} / \mathrm{ml} \mathrm{B.} \mathrm{monnieri} \mathrm{substantially}$
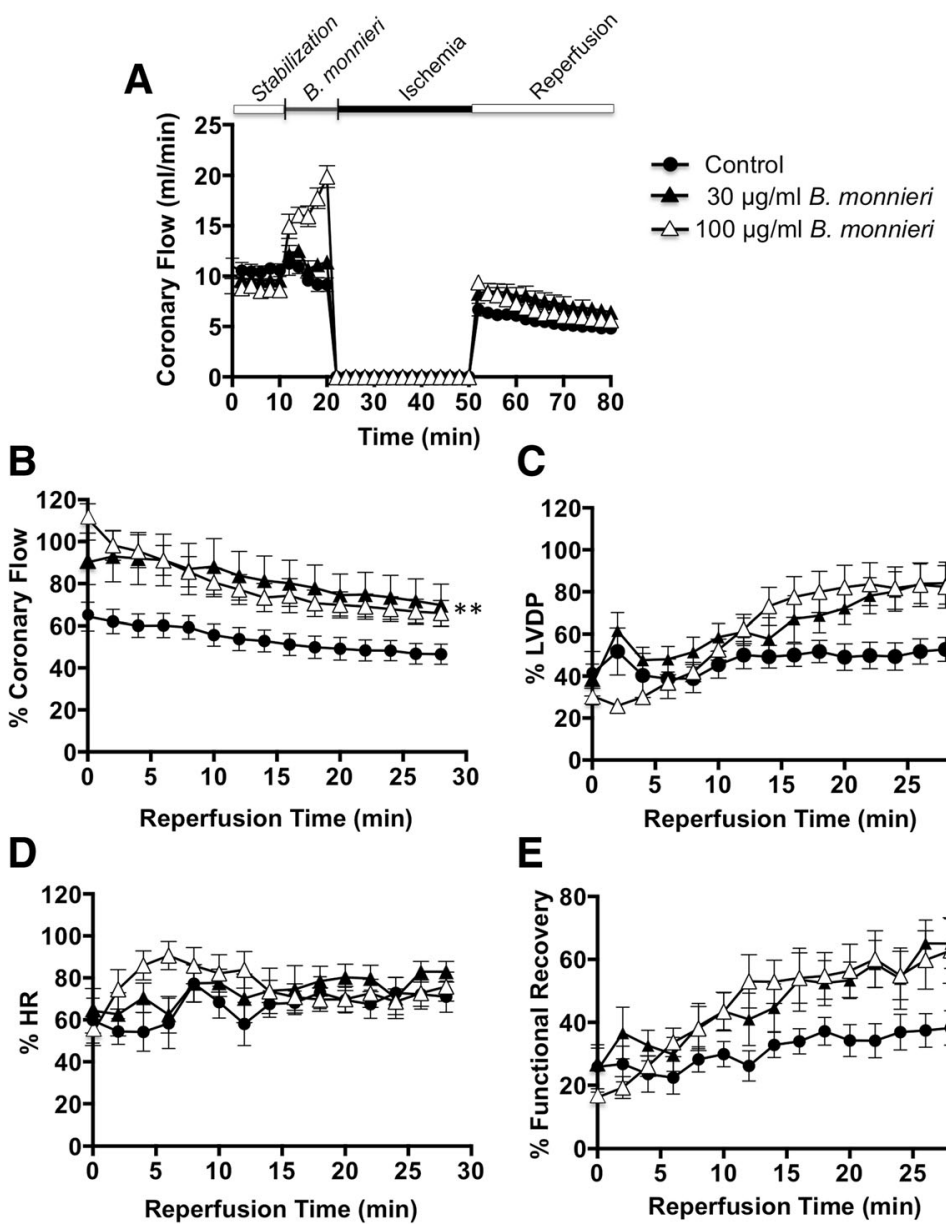

$\rightarrow 100 \mu \mathrm{g} / \mathrm{ml}$ B. monnieri

\section{straxy \\ 7080}

C

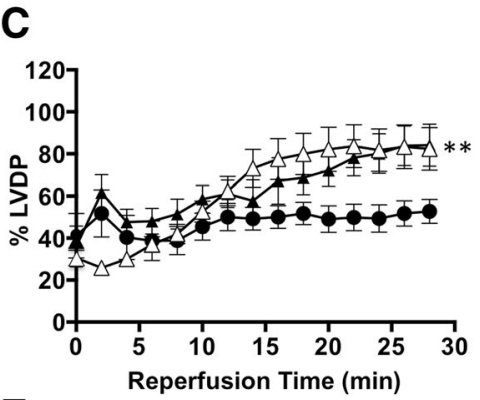

E

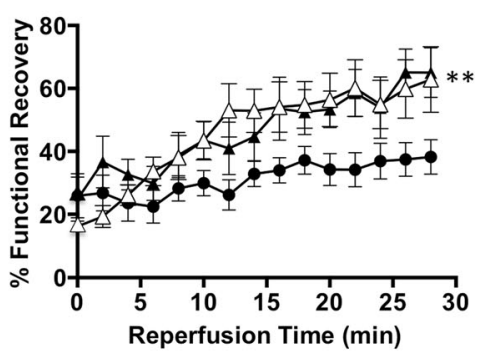

Fig. 2 Pretreatment with B. monnieri and recovery after myocardial ischemia in isolated rat hearts. a coronary flow (ml/min) using normal perfusate (control) or perfusate containing 30 or $100 \mu \mathrm{g} / \mathrm{ml} \mathrm{B.} \mathrm{monnieri}(10 \mathrm{~min})$, followed by cessation of perfusion (30 min, ischemia) and then restoration of normal perfusate (30 min, reperfusion). b-e truncated time courses showing the post-ischemia recovery period where the values are expressed as percentage of the mean data from the same heart compared to the 10 min stabilization using normal perfusate for $\mathbf{b}$ coronary flow, \%, c LVDP, \%, d HR, \% and e functional recovery, \%, a global index of cardiac contractile function, calculated as [(HR TRx $\times$ LVDP TRx $\times 100) /$ HR TP10 $\times$ LVDP TP10] where TRx represents the time of reperfusion at $x$ min and TP10 relates to the value at 10 min of the perfusion during stabilization period. Data are expressed as mean \pm SEM ( $n=9$ hearts) and ${ }^{* *} p<0.001$ for 30 or $100 \mu \mathrm{g} / \mathrm{ml} \mathrm{B.} \mathrm{monnieri} \mathrm{compared} \mathrm{to} \mathrm{control}$ 


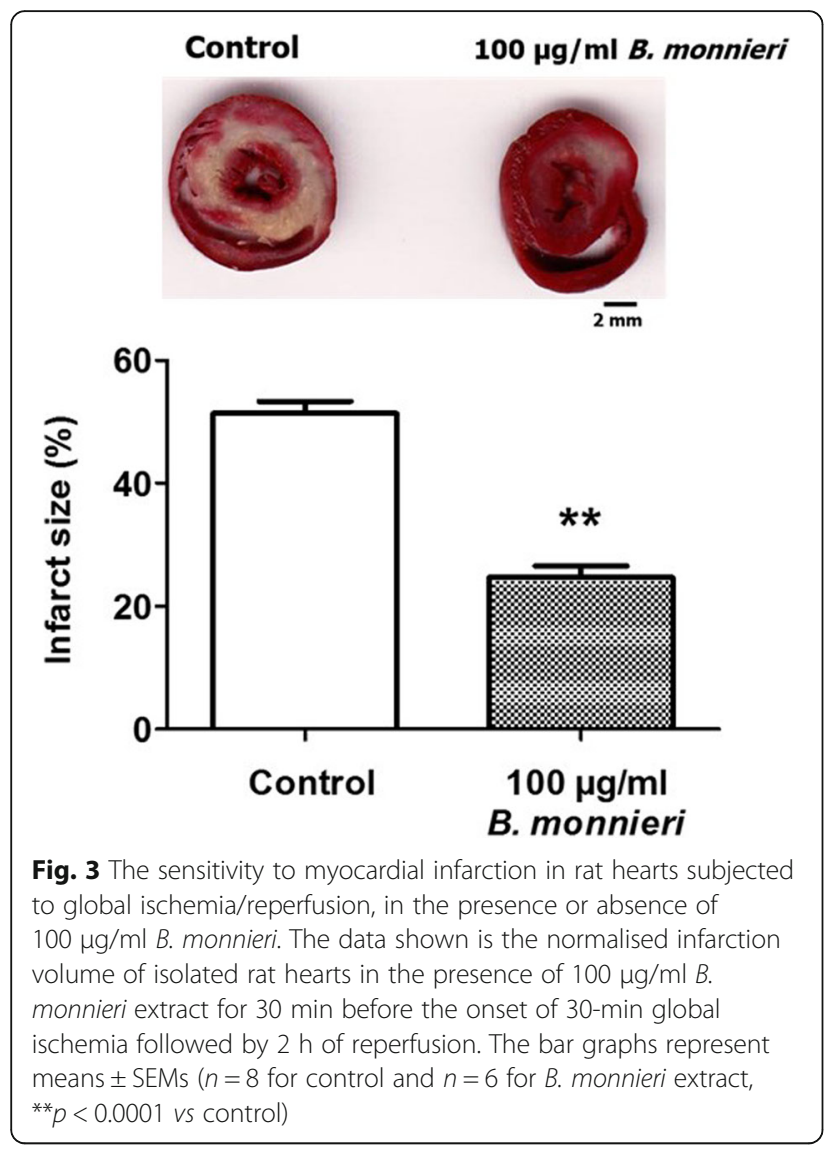

reduced infarct size to $25 \pm 2 \%, n=6$ (Fig. $3, p<0.0001$ vs control).

B. monnieri reduced $\mathrm{I}_{\mathrm{Ca}, \mathrm{L}}$ in $\mathrm{HL}-1$ cardiac cells $\mathrm{Ca}^{2+}$ is an important mediator of ischemic cell damage and in cardiac muscle, an important $\mathrm{Ca}^{2+}$ influx pathway is through L-type $\mathrm{Ca}^{2+}$ channels and blockade of these channels can offer some protection [27, 28].

Whole-cell voltage clamping of HL-1 cardiac cells showed transient inward currents of $-71.4 \pm 19.6 \mathrm{pA}$ previously identified as $\mathrm{I}_{\mathrm{Ca}, \mathrm{L}}$ [25] ('control' in Fig. 4a). The extract decreased the peak current amplitude of $\mathrm{I}_{\mathrm{Ca}, \mathrm{L}}$ to about one third i.e., to $37.1 \pm 4.1 \%$ compared to control ( $p$ $<0.001, n=4$, Fig. 4b).

\section{Cytotoxicity of B. monnieri extract}

Direct effect of $B$. monnieri on cell viability of freshly isolated rat ventricular myocytes was determined using the trypan blue exclusion assay. After $1 \mathrm{~h}$ incubation of ventricular myocytes with various concentrations of $B$. monnieri extract $(10-1000 \mu \mathrm{g} / \mathrm{ml})$, cell survival was decreased in those cells exposed to concentrations of $50 \mu \mathrm{g} / \mathrm{ml}$ and above (Fig. 5). High concentrations of the extract $(\geq 500 \mu \mathrm{g} / \mathrm{ml})$ produced more than $50 \%$ cell death (Fig. 5).
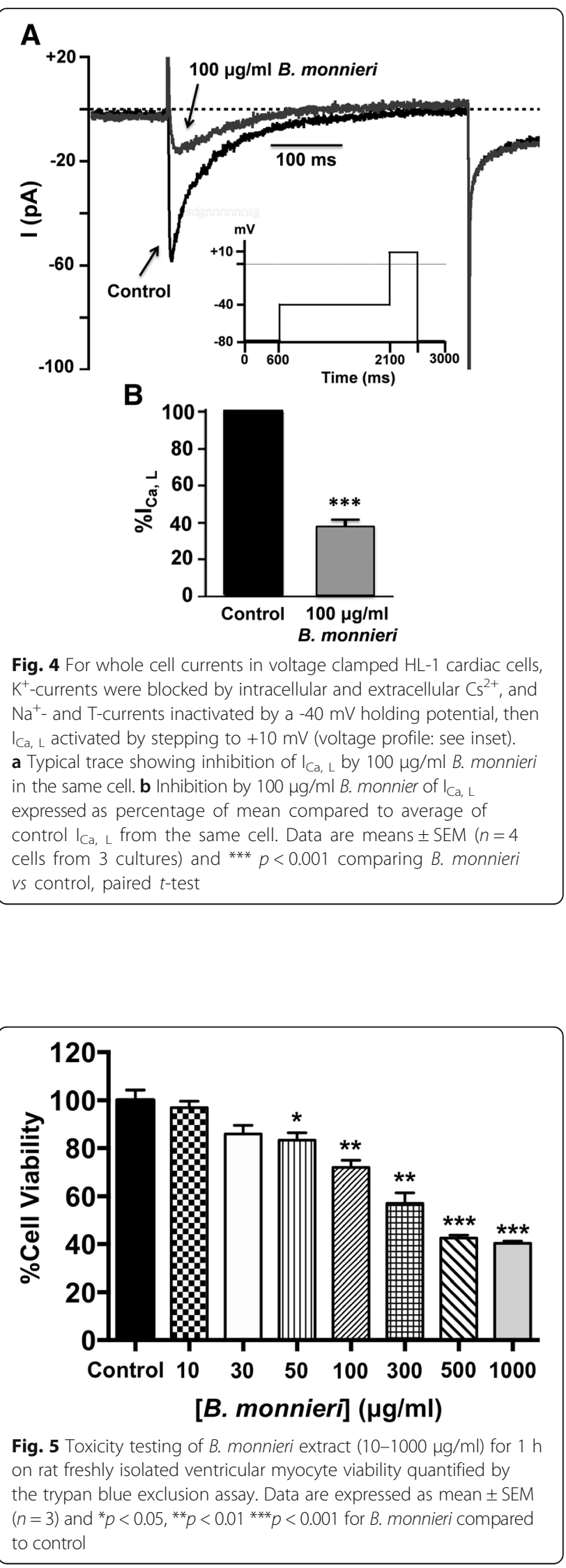


\section{Discussion}

The key findings of the present study were that $B$. monnieri extract induced a concentration-dependent improvement in coronary flow, promoted cardiac function, and reduced infarct area resulting from ischemia and reperfusion in isolated perfused hearts. Previously, B. monnieri was shown to dilate various isolated rat arteries by (i) stimulating endothelial NO release, and (ii) acting directly on vascular smooth muscle cells by inhibiting extracellular $\mathrm{Ca}^{2+}$ influx and $\mathrm{Ca}^{2+}$ release from sarcoplasmic reticulum [11]. Also, B. monnieri inhibits $\mathrm{Ca}^{2+}$ influx in various tissues including several types of isolated rat arteries [11, 29], guinea pig ileum and trachea $[29,30]$ and rat trachea [31]. Similar mechanisms may well operate in the coronary vasculature. Likewise, chronic oral administration of $B$. monnieri increased cerebral blood flow in normal rats [12].

Coronary blood flow is normally mediated by demands of myocardial contraction [32]. However, in the presence of $B$. monnieri coronary flow was substantially greater than the increased LVDP, which suggests that the vasculature dilated independently of myocardial needs. Nevertheless, there was a slightly increased myocardial contractility with $B$. monnieri, which might be facilitated by the augmented blood flow as seen in the canine and rat hearts [33, 34]. Moreover, the positive ionotropic effect of $B$. monnieri suggests the extract had no adverse action on the intact myocardium.

However, there was a clear disconnect between blood flow and contractility during post-ischemic reperfusion: restoration of blood flow was immediate and slowly declined thereafter while LVDP developed over $15 \mathrm{~min}$ (Fig. 2). This implies that contractility was not solely a direct consequence of better blood flow. One explanation for this disconnect could involve $\mathrm{Ca}^{2+}$ influx, which we show was inhibited in isolated myocytes. On the one hand, inhibition of vascular smooth muscle L-type $\mathrm{Ca}^{2+}$ maximises the vasodilatation through the lingering action of $B$. monnieri, thus providing metabolic resources to re-establish the extraand intracellular milieu. At the same time, this same action on cardiac myocytes inhibits their contraction until the accumulated $\mathrm{Ca}^{2+}$ is cleared after which they can re-establish sinus rhythm. This $\mathrm{Ca}^{2+}$ overloading of cardiac myocytes has been emphasised in many studies and various drugs targeting this overload including $\mathrm{Ca}^{2+}$-channel blockers improve post-IR recovery $[27,28]$.

Our present protocol was short-term but B. monnieri may well have more lasting beneficial effects in vivo $[9,10]$. For example, in coronary $I / R$, there is inflammation beginning with endothelial cell blebbing and swelling followed by platelet and leucocyte adhesion leading to microvascular block and a "no flow" condition lasting many hours [7].
With B. monnieri, the initial flow was good but gradually decreased with continued reperfusion for all three treatment groups although the pretreated ones maintained superior flow rates (Fig. 2). The prolonged effects of inflammation do not apply to the present protocol, but our data suggest that the coronary vasculature enters this critical period with a distinct functional advantage. These antiinflammatory effects of $B$. monnieri may be mediated through one of its constituents, betulinic acid $[35,36]$ by potently blocking the inflammatory transcription factor NF-kB or p38/ERK MAPK pathways [35] thereby preventing the augmented cytokine production [36].

Antioxidant actions are universally claimed to be an action of most herbals including B. monnieri $[9,17]$. Yet, whatever of this antioxidant remained in the tissue on reperfusion without extract would have little real impact on the superoxide onslaught. Nevertheless, polyphenols and other plant biologicals stereospecifically cause Nrf-2 nuclear translocation thereby increasing expression of some anti-oxidant enzymes [37-40] and their activation can provide protection against I/R [41].

Our B. monnieri extract appeared to be cytotoxic at a threshold concentration of $\sim 50 \mu \mathrm{g} / \mathrm{ml}$ but, nevertheless, it increased LVDP suggesting that toxicity was absent in the intact myocardium. The explanation for this discrepancy may be a combination of: (i) toxicity was studied in culture where myocytes are directly exposed to the extract, while in the perfused heart the concentration of the extract within the extracellular space is likely to be lower, (ii) the incubation time of cultured myocytes in the extract was longer $(1 \mathrm{~h})$ than the 10 min perfusion. Importantly, the intriguing notion is that if those components of $B$. monnieri having beneficial and having cytotoxic actions are different, the cardioprotective components could display a greater efficacy for postischemic recovery.

This study has revealed an improved coronary flow, increased myocardial function and contracted infarct area. The additional anti-inflammatory, antioxidant defenses and reduced $\mathrm{Ca}^{2+}$-overload demonstrated in other systems, suggest that $B$. monnieri might provide a multipronged defense against ischemic cell death. Nevertheless, the model used here, and most of the animal models for $I / R$ poorly replicate the human condition where the underlying vascular pathology develops over a generation and is influenced by 'conditioning'. Thus, major impacts in the treatment of $\mathrm{I} / \mathrm{R}$ will only become translatable when accurate animal models for the human condition emerge.

\section{Conclusion}

B. monnieri protected against $\mathrm{I} / \mathrm{R}$ injury in rat heart as judged by its ability to recover coronary flow, contractile force and function, and reduced infarct volume. As such, 
it could form the basis of a promising cardioprotectant (and cerebroprotectant) for patients at risk from infarcts. In pursuing this, the protectant and cytotoxic components need to be identified and plant strains or extraction protocols showing more efficacious chemical profiles selected.

\section{Additional file}

Additional file 1: Figure S1. Effect of L-Type $\mathrm{Ca}^{2+}$ Channel Blocker,

Nifedipine, on $I_{C a}$, L current. (DOCX $118 \mathrm{~kb}$ )

\section{Abbreviations}

B. monnieri: Bacopa monnieri; HR: Heart rate; I/R: Ischemia/reperfusion; KHB: Krebs-Henseleit buffer; LVDP: Left ventricular developed pressure; LVEDP: Left ventricular end diastolic pressure; MI: Myocardial infarction; NADPH: Nicotinamide adenine dinucleotide phosphate; NO: Nitric oxide; PBS: Phosphate buffer saline; TP10: The value at $10 \mathrm{~min}$ of the perfusion during stabilization period; TRx: Time of reperfusion at x min; TTC: Triphenyltetrazolium chloride

\section{Acknowledgements}

The authors would like to thank National Research Council of Thailand for financial support and Ministry of Science and Technology, Thailand for providing Ph.D. travelling grant for carrying out research in France and Switzerland.

\section{Funding}

This work was supported by National Research Council of Thailand (R2555B001).

\section{Availability of data and materials}

The data are included within this article and are available from the corresponding author on reasonable request.

\section{Authors' contributions}

SS made substantial contribution to performing most of experiments and data analysis. SD and CD designed, analysed and interpreted the data of effect of B. monnieri on cardiac hemodynamic parameters. SK carried out study of B. monnieri effect on myocardial infarct size and its cytotoxicity, analyzed the data and drafted manuscript. NU and EN designed, analysed and interpreted the data of the effect of $B$. monnieri on $I_{C a}, L$ of $H L-1$ cells. $\mathrm{KI}$ prepared plant extract. NK carried out study of $B$. monnieri effect on myocardial infarct size and analysed the data. NS interpreted the data, drafted and critically revised the manuscript. ST interpreted the data. KC significantly contributed to the concept, designs of all experimental protocols, data analysis and interpretation, drafted and finalised the manuscript. All authors reviewed and approved the final manuscript.

\section{Competing interests}

The authors declare that they have no competing interests.

\section{Consent for publication}

Not applicable.

\section{Ethics approval}

All experimental protocols were approved by the Animal Ethics Committee (No. NU-AE530613 and NU-AE590203), Naresuan University, Phitsanulok, Thailand and by the local committee for ethics in animal experimentation (No. 2012-012-CD, date 05/09/2012), Faculty of Medicine and Pharmacy, Université de Franche Comte, Besançon, France, and complied with the US National Institutes of Health (NIH publication No. 85-2, revised 1996).

\section{Author details}

'Department of Physiology, Faculty of Medicine, Siriraj Hospital, Mahidol University, Bangkok 10700, Thailand. ${ }^{2}$ Department of Physiology, Faculty of Medical Science, Naresuan University, Phitsanulok 65000, Thailand. ${ }^{3}$ PEPITE EA4267, University Bourgogne Franche-Comté, Besançon F-25000, France.
${ }^{4}$ Department of Medical Technology, Faculty of Allied Health Sciences, Naresuan University, Phitsanulok 65000, Thailand. ${ }^{5}$ Biomedical Research Unit in Cardiovascular Sciences, Faculty of Allied Health Sciences, Naresuan University, Phitsanulok 65000, Thailand. ${ }^{6}$ Department of Physiology, University of Bern, Bühlplatz 5, Bern CH-3012, Switzerland. ${ }^{7}$ Department of Physiology and Pathophysiology, Heidelberg University, Heidelberg 69120, Germany. ${ }^{8}$ Department of Pharmaceutical Chemistry and Pharmacognosy, Faculty of Pharmaceutical Sciences, Naresuan University, Phitsanulok 65000, Thailand. ${ }^{9}$ School of Medical Sciences, University of Phayao, Phayao 56000, Thailand.

Received: 19 October 2016 Accepted: 15 February 2017

Published online: 20 February 2017

\section{References}

1. Virmani R, Kolodgie FD, Burke AP, Farb A, Schwartz SM. Lessons from sudden coronary death: a comprehensive morphological classification scheme for atherosclerotic lesions. Arterioscler Thromb Vasc Biol. 2000;20: 1262-75.

2. Frank A, Bonney M, Bonney S, Weitzel L, Koeppen M, Eckle T. Myocardial ischemia reperfusion injury: from basic science to clinical bedside. Semin Cardiothorac Vasc Anesth. 2012:16:123-32.

3. Näpänkangas JP, Liimatta EV, Joensuu P, Bergmann U, Ylitalo K, Hassinen IE. Superoxide production during ischemia-reperfusion in the perfused rat heart: A comparison of two methods of measurement. J Mol Cell Cardiol. 2012;53:906-15.

4. Wagner S, Rokita AG, Anderson ME, Maier LS. Redox regulation of sodium and calcium handling. Antioxid Redox Signal. 2013;18:1063-77.

5. Loppnow H, Buerke M, Werdan K, Rose-John S. Contribution of vascular cellderived cytokines to innate and inflammatory pathways in atherogenesis. J Cell Mol Med. 2011:15:484-500.

6. Montezano AC, Touyz RM. Reactive oxygen species and endothelial function-role of nitric oxide synthase uncoupling and Nox family nicotinamide adenine dinucleotide phosphate oxidases. Basic Clin Pharmacol Toxicol. 2012:110:87-94.

7. Wu KC. CMR of microvascular obstruction and hemorrhage in myocardial infarction. J Cardiovasc Magn Reson. 2012;14:68.

8. Bopassa JC. Protection of the ischemic myocardium during the reperfusion: between hope and reality. Am J Cardiovasc Dis. 2012;2:223-36.

9. Mohanty IR, Maheshwari U, Joseph D, Deshmukh Y. Bacopa monniera protects rat heart against ischaemia-reperfusion injury: role of key apoptotic regulatory proteins and enzymes. J Pharm Pharmacol. 2010; 62:1175-84.

10. Nandave M, Ojha SK, Joshi S, Kumari S, Arya DS. Cardioprotective effect of Bacopa mouneira against isoproterenol-induced myocardial necrosis in rats. Int J Pharmacol. 2007:3:385-92

11. Kamkaew N, Scholfield CN, Ingkaninan K, Maneesai P, Parkington HC, Tare $\mathrm{M}$, et al. Bacopa monnieri and its constituents is hypotensive in anaesthetized rats and vasodilator in various artery types. J Ethnopharmacol. 2011;137:790-5.

12. Kamkaew N, Norman Scholfield C, Ingkaninan K, Taepavarapruk N, Chootip K. Bacopa monnieri increases cerebral blood flow in rat independent of blood pressure. Phytother Res. 2013;27:135-8.

13. Aguiar S, Borowski T. Neuropharmacological review of the nootropic herb Bacopa monnieri. Rejuvenation Res. 2013;16:313-26.

14. Kongkeaw C, Dilokthornsakul $\mathrm{P}$, Thanarangsarit $\mathrm{P}$, Limpeanchob N, Norman SC. Meta-analysis of randomized controlled trials on cognitive effects of Bacopa monnieri extract. J Ethnopharmacol. 2014;151:528-35.

15. Dhanasekaran M, Tharakan B, Holcomb LA, Hitt AR, Young KA, Manyam BV. Neuroprotective mechanisms of ayurvedic antidementia botanical Bacopa monniera. Phytother Res. 2007;21:965-9.

16. Limpeanchob N, Jaipan S, Rattanakaruna S, Phrompittayarat W, Ingkaninan K. Neuroprotective effect of Bacopa monnieri on beta-amyloid-induced cell death in primary cortical culture. J Ethnopharmacol. 2008;120:112-7.

17. Jyoti A, Sethi P, Sharma D. Bacopa monniera prevents from aluminium neurotoxicity in the cerebral cortex of rat brain. J Ethnopharmacol. 2007; 111:56-62.

18. Rastogi M, Ojha RP, Devi BP, Aggarwal A, Agrawal A, Dubey GP. Amelioration of age associated neuroinflammation on long term bacosides treatment. Neurochem Res. 2012;37:869-74. 
19. Sireeratawong $S$, Jaijoy K, Khonsung P, Lertprasertsuk N, Ingkaninan K. Acute and chronic toxicities of Bacopa monnieri extract in SpragueDawley rats. BMC Complement Altern Med. 2016;16:249.

20. Phrompittayarat W, Putalun W, Tanaka H, Jetiyanon K, Wittaya-Areekul S, Ingkaninan K. Determination of pseudojujubogenin glycosides from Brahmi based on immunoassay using a monoclonal antibody against bacopaside I. Phytochem Anal. 2007;18:411-8.

21. Phrompittayarat W, Putalun W, Tanaka H, Wittaya-Areekul S, Jetiyanon K Ingkaninan K. An enzyme-linked immunosorbant assay using polyclonal antibodies against bacopaside I. Anal Chim Acta. 2007;584:1-6.

22. Sutherland FJ, Hearse DJ. The isolated blood and perfusion fluid perfused heart. Pharmacol Res. 2000;41(6):613-27.

23. Kumphune S, Bassi R, Jacquet S, Sicard P, Clark JE, Verma S, et al. A chemical genetic approach reveals that p38alpha MAPK activation by diphosphorylation aggravates myocardial infarction and is prevented by the direct binding of SB203580. J Biol Chem. 2010;285:2968-75.

24. Claycomb WC, Lanson NAJ, Stallworth BS, Egeland DB, Delcarpio JB, Bahinski A, et al. HL-1 cells: a cardiac muscle cell line that contracts and retains phenotypic characteristics of the adult cardiomyocyte. Proc Natl Acad Sci U S A. 1998;95:2979-84.

25. Ullrich ND, Valdivia HH, Niggli E. PKA phosphorylation of cardiac ryanodine receptor modulates SR luminal Ca2+ sensitivity. J Mol Cell Cardiol. 2012;53: 33-42.

26. Strijdom H, Genade S, Lochner A. Nitric oxide synthase (NOS) does not contribute to simulated ischaemic preconditioning in an isolated rat cardiomyocyte model. Cardiovasc Drugs Ther. 2004;18:99-112.

27. Kleinbongard $\mathrm{P}$, Baars $\mathrm{T}$, Heusch $\mathrm{G}$. Calcium antagonists in myocardial ischemia/reperfusion-update 2012. Wien Med Wochenschr. 2012;162: 302-10.

28. Lishmanov YB, Maslov LN, Mukhomedzyanov AV. Role of $\beta$-Adrenoceptors and L-Type $\mathrm{Ca}(2+)$-Channels in the mechanism of reperfusion-induced heart injury. Bull Exp Biol Med. 2016;161(1):20-3.

29. Dar A, Channa S. Calcium antagonistic activity of Bacopa monniera on vascular and intestinal smooth muscles of rabbit and guinea-pig. J Ethnopharmacol. 1999;66:167-74.

30. Dar A, Channa S. Relaxant effect of ethanol extract of Bacopa monniera on trachea, pulmonary artery and aorta from rabbit and guinea-pig. Phytother Res. 1997;11:323-5.

31. Channa S, Dar A, Yaqoob M, Anjum S, Sultani Z, Rahman A-U. Bronchovasodilatory activity of fractions and pure constituents isolated from Bacopa monniera. J Ethnopharmacol. 2003;86:27-35.

32. Deussen A, Ohanyan V, Jannasch A, Yin L, Chilian W. Mechanisms of metabolic coronary flow regulation. J Mol Cell Cardiol. 2012;52:794-801.

33. Abel RM, Reis RL. Effects of coronary blood flow and perfusion pressure on left ventricular contractility in dogs. Circ Res. 1970;27:961-71.

34. Vassallo PF, Stefanon I, Rossoni LV, Tucci PJ, Vassallo DV. The left ventricular contractility of the rat heart is modulated by changes in flow and alpha 1-adrenoceptor stimulation. Braz J Med Biol Res. 1998;31:1353-9.

35. Viji V, Shobha B, Kavitha SK, Ratheesh M, Kripa K, Helen A. Betulinic acid isolated from Bacopa monniera (L.) Wettst suppresses lipopolysaccharide stimulated interleukin-6 production through modulation of nuclear factorkappaB in peripheral blood mononuclear cells. Int Immunopharmacol. 2010; 10:843-9.

36. Zhao G-J, Tang S-L, LV Y-C, Ouyang X-P, He P-P, Yao F, et al. Antagonism of betulinic acid on LPS-mediated inhibition of ABCA1 and cholesterol efflux through inhibiting nuclear factor-kappaB signaling pathway and miR-33 expression. PloS One. 2013;8(9):e74782.

37. Dwivedi S, Nagarajan R, Hanif K, Siddiqui HH, Nath C, Shukla R. Standardized extract of Bacopa monniera attenuates okadaic acid induced memory dysfunction in rats: effect on Nrf2 pathway. Evid Based Complement Alternat Med. 2013;2013:294501.

38. Hybertson BM, Gao B, Bose SK, McCord JM. Oxidative stress in health and disease: the therapeutic potential of Nrf2 activation. Mol Aspects Med. 2011; 32:234-46.

39. Prisila Dulcy C, Singh HK, Preethi J, Rajan KE. Standardized extract of Bacopa monniera (BESEB CDRI-08) attenuates contextual associative learning deficits in the aging rat's brain induced by D-galactose. J Neurosci Res. 2012;90: 2053-64.
40. Singh M, Murthy $V$, Ramassamy $C$. Standardized extracts of Bacopa monniera protect against MPP + - and paraquat-induced toxicity by modulating mitochondrial activities, proteasomal functions, and redox pathways. Toxicol Sci. 2012;125:219-32.

41. Deng C, Sun Z, Tong G, Yi W, Ma L, Zhao B, et al. alpha-Lipoic acid reduces infarct size and preserves cardiac function in rat myocardial ischemia/ reperfusion injury through activation of PI3K/Akt/Nrf2 pathway. PloS One. 2013;8(3):e58371.

\section{Submit your next manuscript to BioMed Central and we will help you at every step:}

- We accept pre-submission inquiries

- Our selector tool helps you to find the most relevant journal

- We provide round the clock customer support

- Convenient online submission

- Thorough peer review

- Inclusion in PubMed and all major indexing services

- Maximum visibility for your research

Submit your manuscript at www.biomedcentral.com/submit
Biomed Central 